Check for updates

Cite this: RSC Adv., 2017, 7, 37778

Received 12th May 2017

Accepted 25th July 2017

DOI: $10.1039 / c 7 r a 05386 j$

rsc.li/rsc-advances

\section{Preparation of an ion imprinted functionalized mesoporous silica for rapid and specific absorption $\mathrm{Cr}(\mathrm{III})$ ions in effluents $\dagger$}

\author{
Shuibin Cen, (D) a Weiming $\mathrm{Li}^{\mathrm{c}}{ }^{\mathrm{R}}$ Rong He, ${ }^{\mathrm{d}}$ Jiean Tan, ${ }^{\mathrm{e}}$ Haishui Wang, ${ }^{\text {*a }}$ Chaohai Wei ${ }^{\mathrm{b}}$ \\ and Youwen Tang*e
}

We developed an effective and selective method to remove $\mathrm{Cr}(\mathrm{III})$ ions in acidic effluents. This method used combined ion imprinted technology with mesoporous silica materials. $\mathrm{Cr}(\mathrm{III})$ ion imprinted mesoporous silica (CrIMS) was synthesized and used as an excellent adsorbent. Iminodiacetic acid (IDA) was silanized, and acted as a functional monomer. The chemical groups, thermal stability, porosity and highly ordered morphology of CrIMS were characterized by Fourier transform infrared spectroscopy (FTIR), thermogravimetric analysis (TGA), Brunauer-Emmett-Teller (BET) isotherms, X-ray diffraction (XRD), transmission electron microscopy (TEM) and scanning electron microscopy (SEM). The BrunauerEmmett-Teller (BET) surface area was $856.24 \mathrm{~m}^{2} \mathrm{~g}^{-1}$. The saturated adsorption capacity of CrIMS towards $\mathrm{Cr}(\mathrm{III})$ ions reached up to $63 \mathrm{mg} \mathrm{g}^{-1}$ at pH 4.5. At a concentration of $200 \mathrm{mg} \mathrm{L}^{-1}$, the adsorption of $\mathrm{Cr}(\mathrm{III})$ ions reached equilibrium within $5 \mathrm{~min}$ and $20 \mathrm{~min}$ at pH 4.5 and pH 3.0, respectively. The CrIMS showed highly specific adsorption capacity and the imprinting factor was up to $4.03 \mathrm{at} \mathrm{pH} 3.0$. The adsorption capacity of $\mathrm{Cr}(\mathrm{III})$ ions was remarkably higher than other co-existing metal ions. After eight adsorption-regeneration cycles, the adsorption efficiency of CrIMS still reached above $94.1 \%$. The CrIMS could effectively remove $\mathrm{Cr}(\mathrm{II})$ ions below the discharge standard of China in real sample treatment.

\section{Introduction}

Electroplated chromium coatings are widely used, thanks to their excellent properties. The hexavalent $\mathrm{Cr}$ has been applied for many years in traditional techniques. Because of the serious toxicity of $\mathrm{Cr}(\mathrm{VI}), \mathrm{Cr}(\mathrm{III})$ has been applied as a substitute in more environmentally friendly processes. ${ }^{1}$ Besides, chromium is widely used in many other industries, such as wood preservation, leather tanning, textiles, metallurgy, and pigments. ${ }^{2}$ Chromium is easily converted to a serious pollutant and is harmful to the environment during widespread use. ${ }^{3,4} \mathrm{Cr}(\mathrm{III})$ ions usually exist in effluents from many industries and excessive emissions can also pollute the environment, although the toxicity of $\mathrm{Cr}(\mathrm{III})$ ions is much lower. On the other hand, $\mathrm{Cr}(\mathrm{III})$

${ }^{a}$ School of Chemistry and Chemical Engineering, South China University of Technology, Guangzhou 510641, China. E-mail: wanghsh@scut.edu.cn

${ }^{b}$ The Key Lab of Pollution Control and Ecosystem Restoration in Industry Clusters, Ministry of Education, South China University of Technology, Guangzhou, China

'Technical Service Center Laboratory of Panyu Entry-Exit Inspection \& Quarantine Bureau, Guangzhou, China

${ }^{d}$ Guangzhou Center for Disease Control and Prevention, Guangzhou 510440, China ${ }^{e} \mathrm{MOE}$ Key Laboratory of Laser Life Science, School of Chemistry and Environment, South China Normal University, 510631, Guangzhou, China. E-mail: tanglab@scnu. edu.cn

$\dagger$ Electronic supplementary information (ESI) available. See DOI: $10.1039 / \mathrm{c} 7 \mathrm{ra} 05386 \mathrm{j}$ can transform to $\mathrm{Cr}(\mathrm{vI})$, resulting from the effects of $\mathrm{pH}$, oxidizing agent $\left(\mathrm{O}_{2}\right)$ and so on. ${ }^{4}$ Thus, chromium continues to enter food chain organisms, which may lead to carcinogenic, allergenic and mutagenic effects. ${ }^{5,6}$ Therefore, it is necessary to design a safe and clean procedure for the efficient removal of $\mathrm{Cr}$ (III) ions from effluents.

Various methods and technologies to remove $\mathrm{Cr}(\mathrm{III})$ ions or other metal ions from effluents to an acceptable concentration level have been investigated, such as liquid-liquid extraction, ${ }^{7}$ ion-exchange, ${ }^{8}$ adsorption, ${ }^{9}$ chemical precipitation ${ }^{9}$ and electrochemical reduction..$^{10}$ However, the use of organic solvent is inevitable during liquid-liquid extraction. Besides, the electrochemical reduction requires extra electrical energy. Among these methods, adsorption has been regarded as the most promising and widely used method due to its high efficiency, simplicity, economy, and environmentally friendly behavior. Activated carbons and low cost adsorbents, such as agricultural residues $^{11}$ and natural products ${ }^{12}$ can also act as adsorbents. These adsorbents usually have low loading capacities and weak interactions with metallic cations. ${ }^{13,14}$ Inorganic/organic hybrid materials, ${ }^{15}$ chelating resin ${ }^{16}$ and carbon nanotubes ${ }^{17}$ have been investigated as adsorbents used in the removal of $\operatorname{Cr}(\mathrm{III})$ ions and other heavy ions from effluents. However, the designs of the above adsorption materials seldom consider the structure of the target and the characteristics of effluents, such as acidity, interfering components and initial metal concentration, and 
<smiles>CO[Si](C)(OC)C1CCC1CC1OC1CNCC(=O)O</smiles>

GYLYMO

IDA

\section{GLYHMO-IDA}

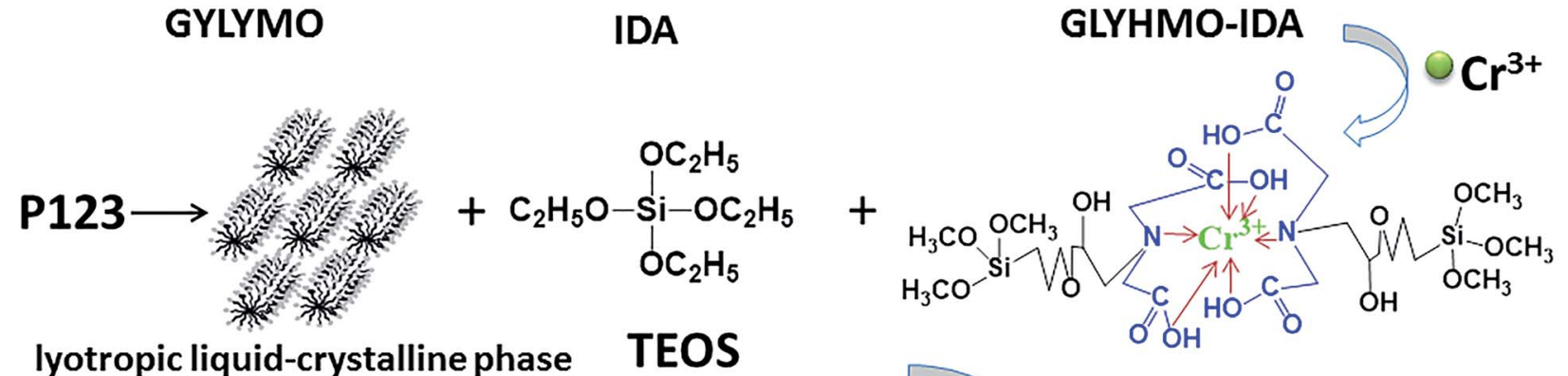

\section{lyotropic liquid-crystalline phase TEOS}
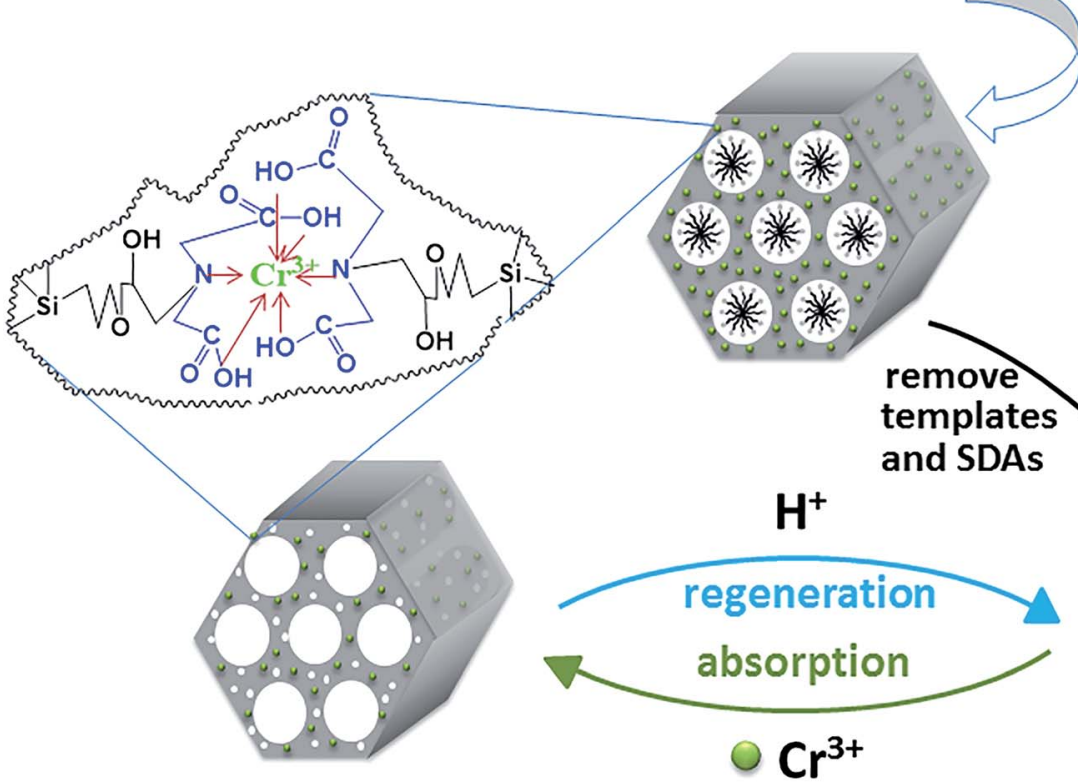

$\mathrm{HCl}$

Scheme 1 Schematic procedure for synthesis of $\mathrm{Cr}^{3+}$ imprinted mesoporous silica. [GLYMO: (3-glycidyloxypropyl) trimethoxysilane, IDA: iminodiacetic acid, P123: poly(ethylene glycol)-block-poly(-propylene glycol)-block-poly(ethylene glycol), TEOS: tetraethoxysilane, SDAs: structure-directing agents].

there are always some limitations in their practical applications. ${ }^{18}$ Therefore, searching for more effective adsorbents to remove heavy metal ions requires a continuous effort for many researchers.

Mesoporous materials possess the large internal surfaces, which highly enhance the capacity of catalytic, absorptivity and the speed of mass transfer. Mesoporous silica, one of typical mesoporous materials, is a kind of an inexpensive and robust porous silica-based solid. Since a new family of mesoporous molecular sieves was prepared with liquid crystal templates in $1992,{ }^{19}$ ordered mesoporous silica has attracted much concern in different fields, due to their uniform pore sizes within the range of a few nanometers and their large surface areas. Ordered mesoporous silica complements conventional zeolites in applications, including adsorption, ${ }^{20}$ catalysis, ${ }^{21}$ drug delivery ${ }^{22}$ and sensing. ${ }^{23}$ MCM-41 and MCM-48, ${ }^{24}$ which have been synthesized at high $\mathrm{pH}$ by using cationic surfactants templates, are the two common series of mesoporous silica.
Besides, anionic and nonionic surfactants have also attracted interest as templates for mesoporous materials. Silica precursors usually need to be hydrolyzed in low $\mathrm{pH}$ (SBA-15, SBA-16). ${ }^{25}$ SBA-15 possesses thicker framework walls than MCM-41, and thus exhibits a higher thermal and hydrothermal stability. Therefore, SBA-15, synthesized in strongly acidic medium, makes it a good candidate as an adsorbent support material for removal of $\mathrm{Cr}$ (III) ions from acidic effluents. Many researches have focused on modification of SBA-15 by some functional groups (e.g. carboxyl, amine), ${ }^{26}$ but the simple modified mesoporous silica hardly possess specific recognition ability for $\mathrm{Cr}(\mathrm{III})$ ions and high adsorption capacities in acidic medium.

With the pioneering work conducted in the 1990s, molecular imprinting technology(MIT) has increasingly developed ${ }^{27}$ and has attracted considerable attention as a new fabrication technology of bionic receptors. ${ }^{28}$ In general, molecular imprinting polymers (MIPs) are prepared by the copolymerization of functional monomers and cross-linkers in the presence of 
target analytes that act as template molecules, which results in selective cavities in a 3D-polymeric network and shows great affinity with target analytes. ${ }^{29,30}$ Owing to their high selectivity, inherent simplicity, reusability, physical robustness and costeffectiveness, MIPs are widely used in different fields, such as purification and separation, ${ }^{31}$ chemo/biosensing, ${ }^{32}$ drug delivery, ${ }^{33}$ and catalysis. ${ }^{34}$ The molecular imprinting technique has also been applied to prepare ion imprinted polymers (IIPs). ${ }^{35}$ However, traditional IIPs exhibit a low adsorption capacity and poor site accessibility toward targets, as the binding sites are embedded within a highly cross-linked polymer matrix. In order to design high selective adsorbent with large surface areas, applying imprinting technology to mesoporous materials is a promising strategy, which gained considerable interest over the past few years. ${ }^{35,36}$ In those ion imprinted mesoporous silicas, the selectivity toward template metal ions was improved without considering their adsorption capacities in acidic medium. Co-condensation is one of common strategies to modified mesoporous silica materials. ${ }^{37}$ Compared to postsynthetic functionalization (grafting), cocondensation modification is the simultaneous addition of the corresponding silica and structure-directing agents (SDAs) with organosilica precursors and templates. The organofunctional groups covalently anchor in the pore walls, and it can effectively overcome some shortcomings of grafting synthesis, such as the loss of surface area, pore blocking, and heterogeneous distribution of recognition sites. ${ }^{38}$

In this work, we designed and fabricated a novel, highly ordered Cr(III) ions imprinted mesoporous silica (CrIMS) functionalized by iminodiacetic acid (IDA) for directly removing and recycling $\mathrm{Cr}$ (III) in a strongly acidic medium (Scheme 1). IDA and (3-glycidyloxypropyl)trimethoxysilane (GLYMO) were reacted to synthesize a precursor GLYMO-IDA, which acted as the functional monomer. Tetraethoxysilane (TEOS) was chosen as the cross-linker, while P123 was used as the SDAs. The synthetic CrIMS was characterized by small angle X-ray diffraction (XRD), transmission electron microscopy (TEM) and nitrogen adsorption-desorption measurement. Its adsorption behavior in aqueous solutions was investigated and compared with nonimprinted mesoporous silica (NIMS). Eventually, the ability of CrIMS to remove Cr(III) efficiently was demonstrated in highly acidic actual effluents samples.

\section{Materials and methods}

\subsection{Materials}

All reagents and solvents were of AR grade and used without further purification unless otherwise noted. Tetraethoxysilane (TEOS) was obtained from Aladdin Reagent Company (Shanghai, China), while (3-glycidyloxypropyl)trimethoxysilane (GLYMO) was purchased from J\&K-Scientific Chemical Reagent Company (Beijing, China). Poly(ethylene glycol)-block-poly(-propylene glycol)-block-poly(ethylene glycol) (P123, $\mathrm{EO}_{20} \mathrm{PO}_{70^{-}}$ $\mathrm{EO}_{20}$ ) was received from Sigma-Aldrich (Shanghai, China). Iminodiacetic acid (IDA) was obtained from Alfa Aesar (Shanghai, China). Hexamethylene tetraamine, nitric acid, $\mathrm{CrCl}_{3} \cdot 6 \mathrm{H}_{2} \mathrm{O}, \quad \mathrm{ZnCl}_{2} \cdot 6 \mathrm{H}_{2} \mathrm{O}, \mathrm{CdCl}_{2} \cdot 2.5 \mathrm{H}_{2} \mathrm{O}, \mathrm{Cu}\left(\mathrm{NO}_{3}\right)_{2} \cdot 3 \mathrm{H}_{2} \mathrm{O}$,
$\mathrm{Pb}\left(\mathrm{NO}_{3}\right)_{2}, \mathrm{MnCl}_{2} \cdot 4 \mathrm{H}_{2} \mathrm{O}$ and $\mathrm{FeCl}_{3} \cdot 6 \mathrm{H}_{2} \mathrm{O}$, were provided by Tianjin Chemical Reagent Company (Tianjin, China). Doubly distilled water (DDW) was used for all dilutions except for the real sample.

\subsection{Preparation of GLYMO-IDA silane}

GLYMO-IDA silane was prepared basing on a published method with some modifications. ${ }^{18}$ IDA (30 mmol) and $50 \mathrm{~mL}$ of DDW were mixed in a $100 \mathrm{~mL}$ single-necked flask. The $\mathrm{pH}$ of the solution was then adjusted to 11 with $10 \mathrm{~mol} \mathrm{~L}^{-1} \mathrm{NaOH}$. Then, the flask was cooled by using ice-bath and $6 \mathrm{mmol}$ of GLYMO was slowly mixed in the solution. The mixture was heated in water-bath at $65^{\circ} \mathrm{C}$ for $6 \mathrm{~h}$ with stirring, followed by cooling the resultant in an ice-bath for $10 \mathrm{~min}$. When the temperature of the resultant dropped to $0{ }^{\circ} \mathrm{C}, 6 \mathrm{mmol}$ of GLYMO was further added slowly with vigorous stirring. The mixture was heated in waterbath at $65{ }^{\circ} \mathrm{C}$ for $6 \mathrm{~h}$ with stirring, again. Similarly, $7 \mathrm{mmol}$ of GLYMO was again added into the above mixture and incubated overnight with stirring at $65{ }^{\circ} \mathrm{C}$. Finally, the pH of the GLYMOIDA-silane solution was adjusted to 6 by using concentrated $\mathrm{HNO}_{3}$. This synthesized compound solution was stored in a refrigerator at $4{ }^{\circ} \mathrm{C}$.

\subsection{Preparation of CrIMS and NIMS}

$\mathrm{CrCl}_{3}(1 \mathrm{mmol})$ and GLYMO-IDA ( $\left.2 \mathrm{mmol}\right)$ were mixed in $10 \mathrm{~mL}$ of DDW and stirred at $40{ }^{\circ} \mathrm{C}$ for $2 \mathrm{~h}$ to form a pre-assembly solution. Meanwhile, $2.0 \mathrm{~g}$ of $\mathrm{P} 123$ and $10 \mathrm{~mL}$ of $12 \mathrm{~mol} \mathrm{~L}^{-1}$ hydrochloric acid were mixed in $50 \mathrm{~mL}$ of DDW and kept stirring for $2 \mathrm{~h}$ at $40{ }^{\circ} \mathrm{C}$. The pre-assembly solution was dropped into this solution. The mixed solution was kept stirring for $1 \mathrm{~h}$. Then, TEOS (15 mmol) was dropped into the mixture and the mixture was kept stirring for $12 \mathrm{~h}$. The resultant solution was transferred into a hydrothermal reactor and reacted at $85^{\circ} \mathrm{C}$ for $48 \mathrm{~h}$. The collected products were eluted by using Soxhlet extraction with an ethanol-hydrochloric acid solution $(9: 1, \mathrm{v} / \mathrm{v})$ to remove the $\mathrm{Cr}$ (III) ions and the surfactant. After that, the final CrIMS was acquired and dried in a drying cabinet. The nonimprinted mesoporous silica (NIMS) was synthesized in parallel but without the addition of the $\mathrm{Cr}(\mathrm{III})$ ions.

\subsection{Apparatus and analytical conditions}

Small angle X-ray diffraction (XRD) measurements were conducted with a Bruker D8 Advance Scattering system using $\mathrm{Cu} \mathrm{K \alpha}$ $(\lambda=1.5405 \AA)$ radiation over a range of $0.5-5^{\circ} 2 \theta$. Fourier transform infrared spectra (FTIR) were recorded using a Varian DRX-400 Fourier Transform Spectrophotometer. Transmission electron microscopy (TEM) analysis was performed by using a JEM-2010HR at $120 \mathrm{kV}$ (JEOL, Japan). Scanning electron microscopy (SEM) images were taken on a ZEISS Ultra 55 microscope. $\mathrm{N}_{2}$ adsorption-desorption measurements were carried out using a surface area and pore size analyzer from Beishide Instrument (Beijing). Surface areas were calculated by the Brunauer-Emmett-Teller (BET) method, and the pore volume and pore size distribution were calculated using the Barrett-Joyner-Halenda (BJH) model. Solid-state ${ }^{13} \mathrm{C}$ and ${ }^{29} \mathrm{Si}$ NMR were carried on a Bruker Ascend III 400 HD. 
Thermogravimetric analysis (TGA) curves were obtained by heating the sample from 30 to $700{ }^{\circ} \mathrm{C}$ at a heating rate of $10{ }^{\circ} \mathrm{C} \min ^{-1}$ under an air atmosphere using a thermogravimetric analyzer (NETZSCH, Germany). Metal ion concentrations were recorded on a Varian 730 ES Inductively Coupled Plasma Emission Spectrometer.

\subsection{Adsorption experiment}

Adsorption experiments were investigated by using $10 \mathrm{mg}$ CrIMS or NIMS and $10 \mathrm{~mL}$ solution at $25{ }^{\circ} \mathrm{C}$. The $\mathrm{pH}$ of the solution was adjusted by using nitric acid-hexamethylenetetramine buffer solution. In the $\mathrm{pH}$ test, CrIMS or NIMS were added at a different $\mathrm{pH}(2.0-6.0)$ of $\mathrm{Cr}$ (III) ions solution $(200 \mathrm{mg}$ $\mathrm{L}^{-1}$ ) in each vial. The calculated imprinting factor (IF) was defined as IF $=B_{\mathrm{i}} / B_{\mathrm{n}}$, where $B_{\mathrm{i}}$ and $B_{\mathrm{n}}$ represented the binding capacity of CrIMS and NIMS, respectively. After each adsorption cycle, the CrIMS or NIMS were separated by centrifugation, and the residual concentration of $\mathrm{Cr}(\mathrm{III})$ ions in the supernatant was measured. All the adsorption experiments were conducted in triplicate, and the mean values are reported.

The isothermal adsorption experiments were carried out by using a series of $\mathrm{Cr}$ (III) ions solution in the range of 1 to $400 \mathrm{mg} \mathrm{L}^{-1}$. The adsorption kinetics tests were performed using $\mathrm{Cr}$ (III) ions solutions of two different concentrations (20 and $\left.200 \mathrm{mg} \mathrm{L}^{-1}\right)$. After shaking for regular time, the CrIMS was separated, and the residual concentration of $\mathrm{Cr}(\mathrm{III})$ ions in the solution was measured by ICP-MS.

In order to measure selectivity of the CrIMS, the mixed solutions containing $\mathrm{Cr}^{3+}, \mathrm{Zn}^{2+}, \mathrm{Cd}^{2+}, \mathrm{Cu}^{2+}, \mathrm{Pb}^{2+}, \mathrm{Mn}^{2+}$ and $\mathrm{Fe}^{3+}$ $\left(1 \mathrm{mmol} \mathrm{L}^{-1}\right.$ ) were used, and the $\mathrm{pH}$ of each solution was maintained at 4.5.

\subsection{Reusability and reproducibility}

$\mathrm{Cr}$ (III) ions solution of concentration $200 \mathrm{mg} \mathrm{L}^{-1}$ at $\mathrm{pH} 4.5$ was used for testing the reusability and reproducibility of the CrIMS. In each cycle, the Cr(III) ions absorbed by the CrIMS was eluted with $4 \mathrm{~mL}$ of $2 \mathrm{~mol} \mathrm{~L}^{-1} \mathrm{HCl}$. The CrIMS was washed thrice with DDW, neutralized with $1 \mathrm{~mol} \mathrm{~L}^{-1} \mathrm{NaOH}$, again rinsed thrice with DDW, and dried. The dried CrIMS was then used for the next adsorption cycle. The same CrIMS was reused 8 times for adsorption of $\mathrm{Cr}(\mathrm{III})$ ions to measure its reusability. Additionally, five batches of CrIMS prepared at different times and were employed to evaluate the reproducibility of CrIMS.

\subsection{Removal of $\mathrm{Cr}$ (III) ions from water sample}

The sample of electroplating effluent was collected in a polyethylene bottle from Dawang Electroplating Industrial Park (Guangdong, China) with $\mathrm{pH} 3.0$ and $\mathrm{Cr}$ (III) ions concentration of $26 \mathrm{mg} \mathrm{L}{ }^{-1}$. The water sample was filtered through a $0.45 \mu \mathrm{m}$ micro filtration membrane to remove all impurities. Then, the CrIMS was used to adsorb Cr(III) ions from $10 \mathrm{~L}$ of the effluent. The residual concentration of $\mathrm{Cr}(\mathrm{III})$ ions in the solution was analyzed by ICP-MS. The recycle method of the CrIMS was same as that of the reusability experiment mentioned above.

\section{Results and discussion}

\subsection{Characterization of CrIMS}

3.1.1. FT-IR spectra. The FT-IR spectra of the samples are displayed in Fig. 1. The wide and strong absorption band at $3300 \mathrm{~cm}^{-1}$ was ascribed to the stretching vibration of $\mathrm{O}-\mathrm{H}$ and the absorption band at $1626 \mathrm{~cm}^{-1}$ was attributed to the bending mode of O-H in SBA-15, NIMS and CrIMS. ${ }^{18,39}$ The characteristic peaks of the $\mathrm{Si}-\mathrm{O}-\mathrm{Si}$ group and the $\mathrm{Si}-\mathrm{O}$ are found at $1060 \mathrm{~cm}^{-1}$ and $795 \mathrm{~cm}^{-1}$, which proves that the matrix materials of these three samples are silica. The characteristic peaks of the $\mathrm{C}=\mathrm{O}$ group was found at $1731 \mathrm{~cm}^{-1}$ on the curve of NIMS and CrIMS, confirming that GLYMO-IDA was successfully embedded in the silica matrix.

3.1.2. Solid-state ${ }^{13} \mathrm{C}$ and ${ }^{29} \mathrm{Si}$ NMR spectra. The solid-state ${ }^{13} \mathrm{C}$ NMR spectra of NIMS and CrIMS (Fig. 2) showed the characteristic peaks (peak 1-6), which corresponded to the structure of GLYMO-IDA. The signal of carbon C-1 directly bound to the $\mathrm{Si}$ atom was presented at $7 \mathrm{ppm}$. The resonance peak at $21 \mathrm{ppm}$ corresponded to carbon C-2 of the propyl chain in GLYMO-IDA. The peaks at 56, 64, and 72 ppm could be ascribed to C-5, C-3 and $\mathrm{C}-4$, respectively. The peak for the carboxyl carbons of IDA moieties appeared clearly at $169 \mathrm{ppm} .{ }^{18}$

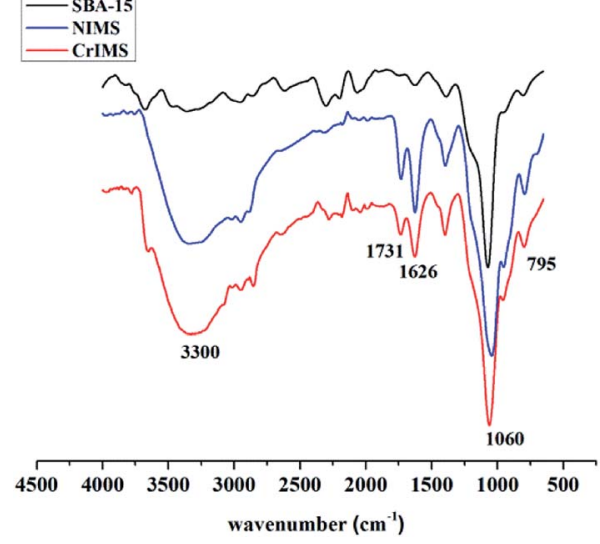

Fig. 1 FT-IR spectra of SBA-15, NIMS and CrIMS.

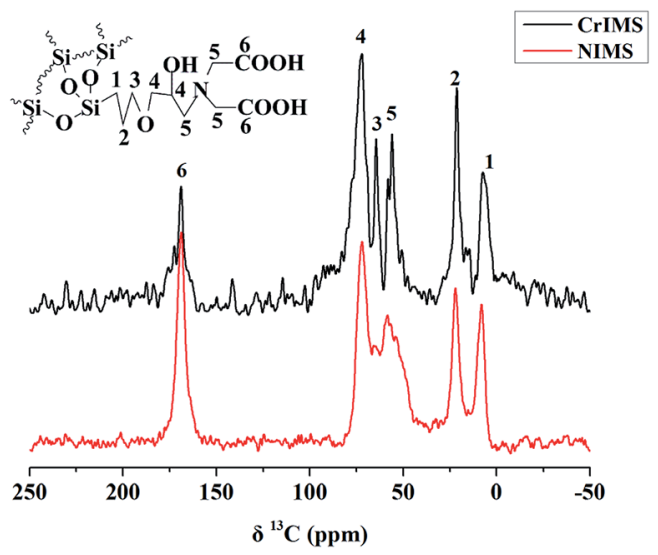

Fig. 2 Solid-state ${ }^{13} \mathrm{C}$ NMR spectrum of CrIMS and NIMS. 


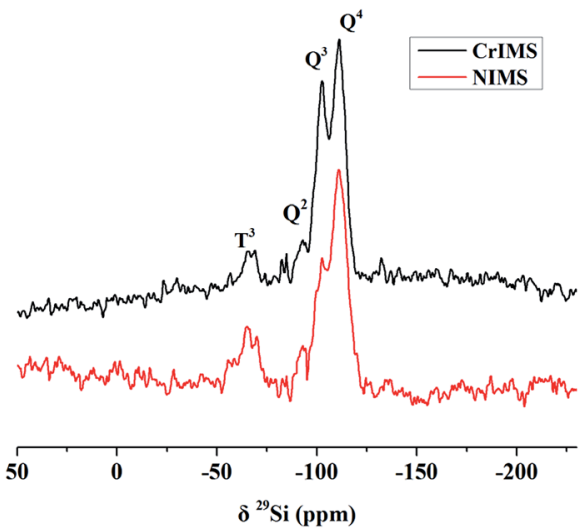

Fig. 3 Solid-state ${ }^{29}$ Si NMR spectrum of CrIMS and NIMS.

The spectra of solid-state ${ }^{29} \mathrm{Si}$ NMR of NIMS and CrIMS (Fig. 3) presented the peaks of $\mathrm{T}^{3}, \mathrm{Q}^{2}, \mathrm{Q}^{3}$ and $\mathrm{Q}^{4}(-65,-93$, -102 and $-111 \mathrm{ppm}$, respectively). The $\mathrm{T}^{3}$ silicon signals represented the structure of $(\mathrm{SiO})_{3} \mathrm{SiR}$, which could be attributed to the Si of functional monomer (GLYMO-IDA). Besides, the peaks of $\mathrm{Q}^{n}(n=2,3$ and 4$)$ corresponded to the structure of ( $\left.\mathrm{SiO}\right)_{n^{-}}$ $\mathrm{Si}(\mathrm{OH})_{4-n}$, which were common signals of mesoporous silica. ${ }^{40,41}$

Based on the analysis of the solid-state ${ }^{13} \mathrm{C}$ and ${ }^{29} \mathrm{Si} \mathrm{NMR,} \mathrm{it}$ could be proved that GLYMO-IDA was successfully incorporated into the mesoporous silica.

3.1.3. XPS analysis. The XPS spectrum of CrIMS is displayed in Fig. 4. The signals of $\mathrm{C}_{1 \mathrm{~s}}$ and $\mathrm{N}_{1 \mathrm{~s}}$ indicated that GLYMO-IDA has been involved in CrIMS. Besides, the signal of Cr was hardly to be detected, which revealed that the $\mathrm{Cr}$ (III) ions were eluted.

3.1.4. XRD patterns. The small angle XRD pattern of CrIMS is shown in Fig. 5. Three characteristic diffraction peaks of (100), (110) and (200) were observed in the region $2 \theta=0.5-2.0^{\circ}$, which revealed that the CrIMS owned a highly ordered 2D mesostructure with typical hexagonal $16 \mathrm{~mm}$ symmetry. Besides, the small angle XRD patterns of CrIMS and NIMS both consistented with the pattern of SBA-15.

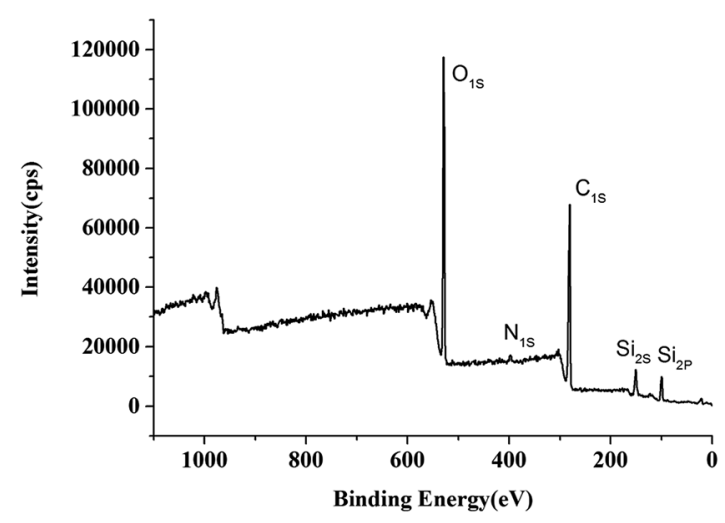

Fig. 4 XPS spectrum of CrIMS

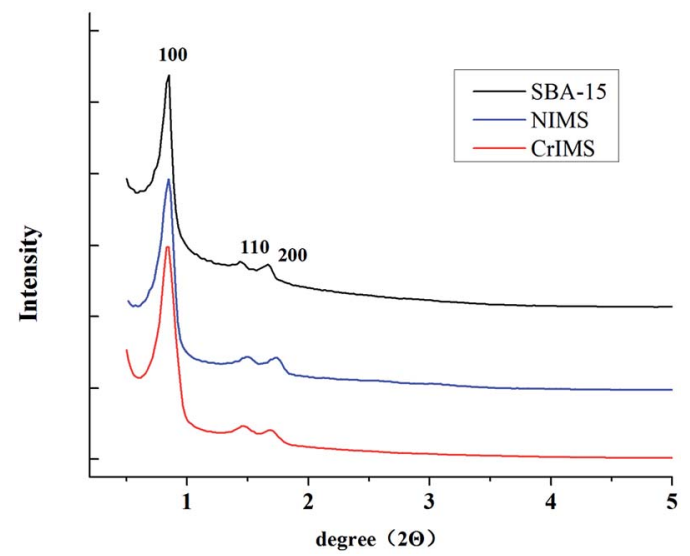

Fig. 5 The low-angle XRD pattern of SBA-15, NIMS and CrIMS

3.1.5. Morphological characteristics. The SEM image (Fig. 6) of CrIMS displayed a regular morphology and were in the shape of short pillars. The TEM image (Fig. 6) revealed that CrIMS persevered ordered porous structure and wellformed hexagonal pore arrays. The average pore diameter was about $6.25 \mathrm{~nm}$ and the average wall thickness is about $3.2 \mathrm{~nm}$. The SEM and TEM images of CrIMS and NIMS (Fig. S1 and $\mathrm{S} 2 \dagger$ ) displayed no significant difference in the highly ordered mesoporous structure (SBA-15) (Fig. S3 and $\mathrm{S} 4 \dagger$ ).

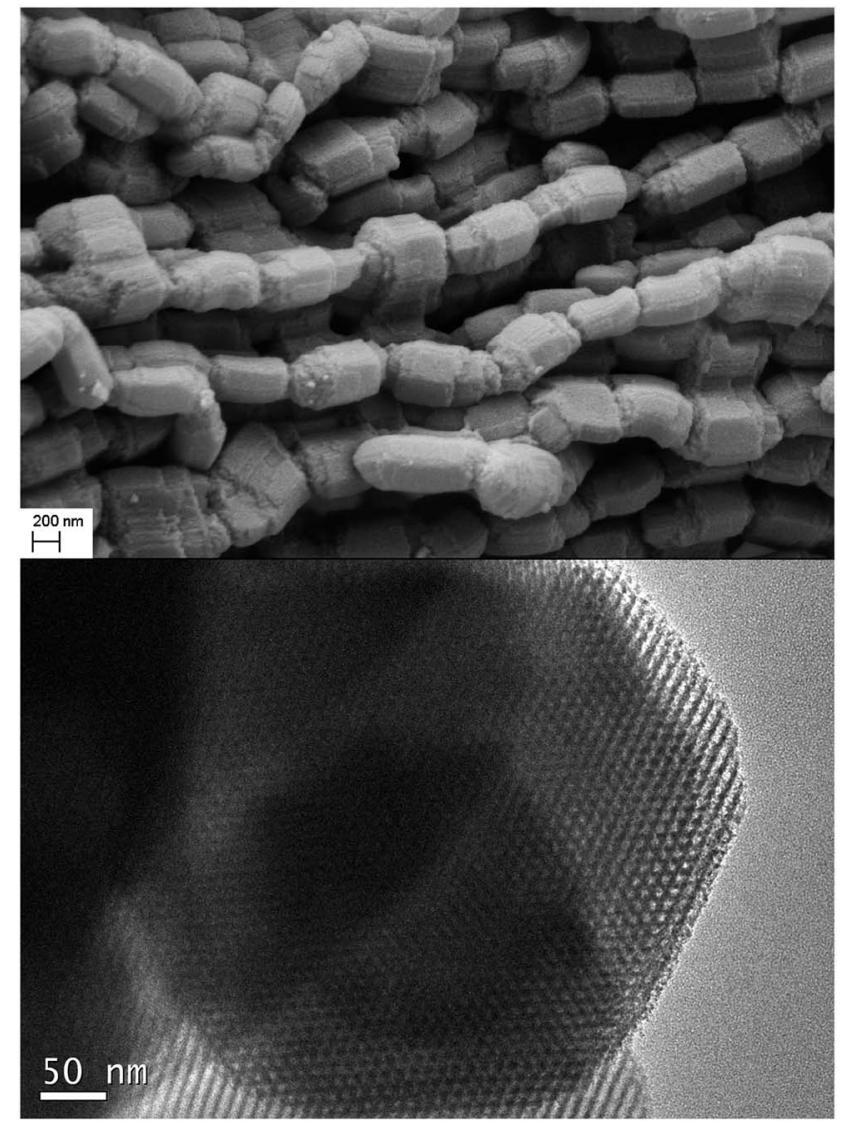

Fig. 6 SEM and TEM image of CrIMS. 


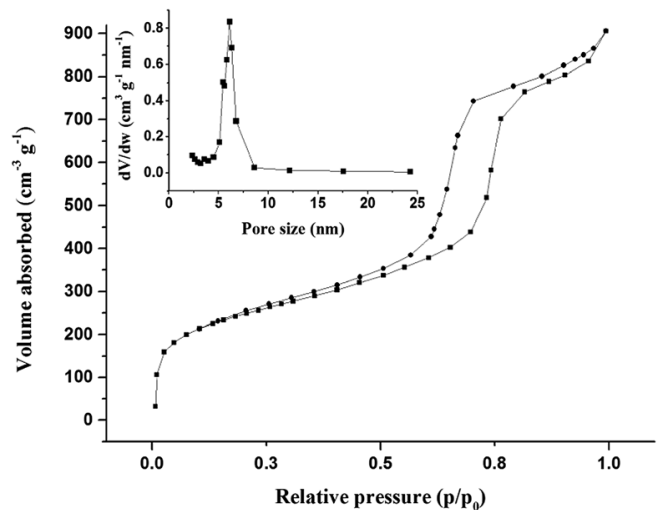

Fig. $7 \quad \mathrm{~N}_{2}$ adsorption-desorption isotherm.

3.1.6. BET analysis. The porous structure of the CrIMS is one of significant factors for the adsorption of $\mathrm{Cr}$ (III) ions. The experiment of $\mathrm{N}_{2}$ adsorption-desorption was carried out to investigate the porosity of CrIMS. A type IV isotherm with a hysteresis loop is displayed in Fig. 7, which confirms mesoporous characteristics. The insert picture in Fig. 7 presented the mean pore size, which was estimated by the Barrett-JoynerHalenda (BJH) method to be $6.55 \mathrm{~nm}$, which was consistent with the TEM image. The Brunauer-Emmett-Teller (BET) surface area was $856.24 \mathrm{~m}^{2} \mathrm{~g}^{-1}$ while the pore volume was $1.45 \mathrm{~cm}^{3} \mathrm{~g}^{-1}$. All of these results confirmed that the resultant CrIMS possessed a typical SBA-15 mesoporous structure.

3.1.7. TGA analysis. The curves of SBA-15 and CrIMS in TGA analysis were displayed in Fig. 8. The weight loss of SBA15 and CrIMS occurred from room temperature to $130{ }^{\circ} \mathrm{C}$, which was attributed to the release of adsorbed water. The second weight loss of SBA-15 (5.35\%) resulted from the loss of the hydroxyl groups. ${ }^{42}$ CrIMS had more obvious second weight loss $(24.67 \%)$, which was mainly caused by the loss of the organic groups from GLYMO-IDA. Based on the weight loss in the TGA analysis, it was indicated that the organic groups from GLYMO-IDA were successfully combined with the silica matrix.

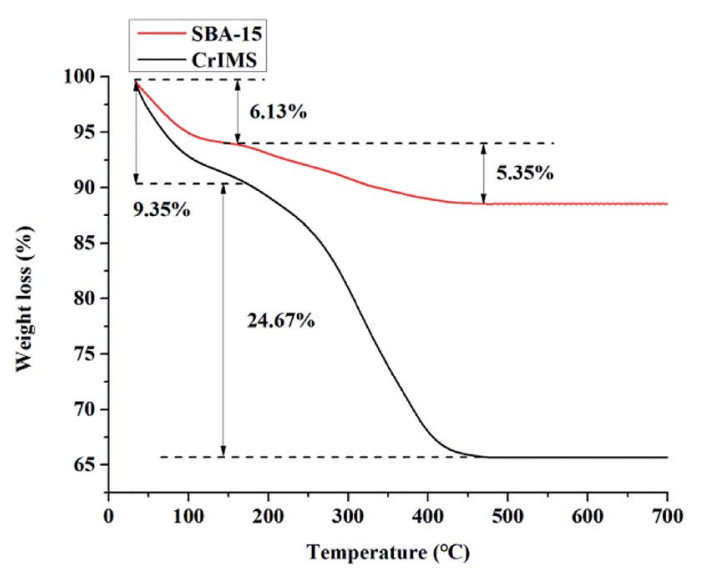

Fig. 8 TGA curves of SBA-15 and CrIMS.

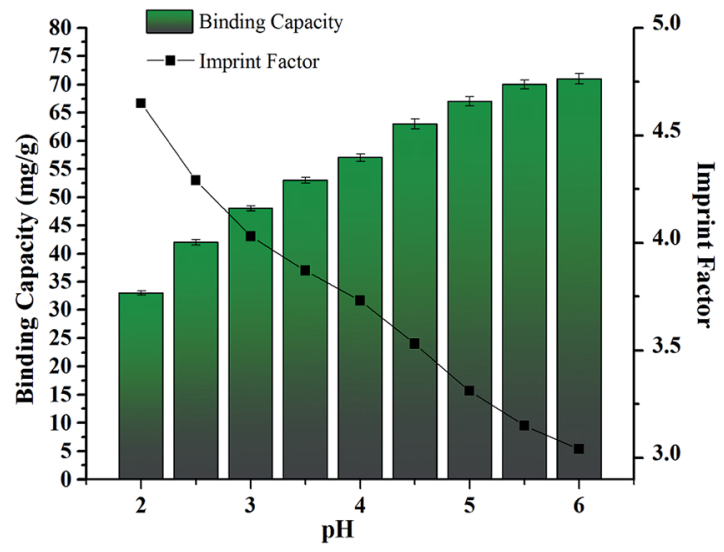

Fig. 9 The effect of $\mathrm{pH}$ on adsorption capacity and IF of CrIMS (experimental conditions: used $10 \mathrm{~mL}$ of $200 \mathrm{mg} \mathrm{L}^{-1} \mathrm{Cr}($ III) ion solution, solid weight $10 \mathrm{mg}, T=298 \mathrm{~K}$ ).

\subsection{Binding study}

The complexation between $\mathrm{Cr}(\mathrm{III})$ ions and IDA groups is distinctly influenced at different pHs. The effects of solution acidity on the adsorbed capacity and the imprinting factor (IF) of CrIMS were investigated. Since Cr(III) ions may convert to $\mathrm{Cr}(\mathrm{OH})_{3}$ at a high $\mathrm{pH}$, the experiment was carried out from $\mathrm{pH}$ 2.0 to $\mathrm{pH}$ 6.0, shown in Fig. 9. The binding capacity of CrIMS toward $\mathrm{Cr}(\mathrm{III})$ ions was positively correlated with the $\mathrm{pH}$, while the IF showed a negative one. The largest adsorption capacity (approximately $71 \mathrm{mg} \mathrm{g}^{-1}$ ) and IF (4.65) was observed at solution $\mathrm{pH}$ of 6.0 and 2.0, respectively. The decrease of binding capacity at lower $\mathrm{pH}$ could be attributed to the protonation of the donating nitrogen atoms and the lower dissociation extent of the carboxyl groups in the imprinting cavities, reducing the extent of complexation between the $\mathrm{Cr}(\mathrm{III})$ ions and the IDA groups. CrIMS possessed imprinting cavities and could specifically adsorb the templates, which was a stronger force compared with the nonspecific adsorption of NIMS. Thus, the IF values tended to be smaller at higher pHs.

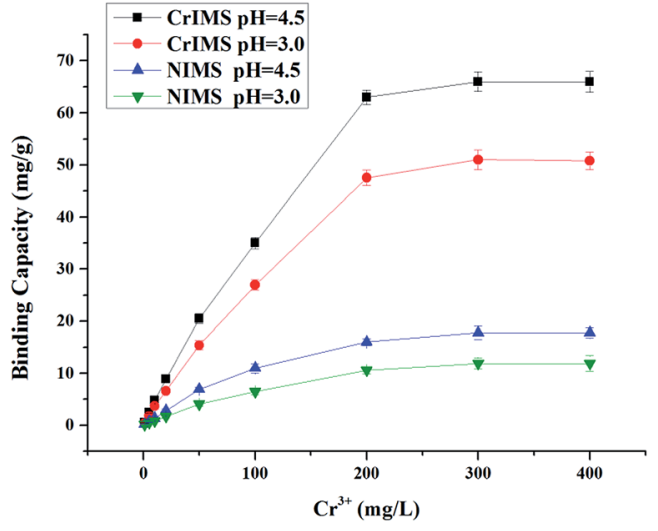

Fig. 10 Adsorption capacity of CrIMS and NIMS(Experimental conditions: used $10 \mathrm{~mL}$ of different concentrations of $\mathrm{Cr}(\mathrm{III})$ ion solution, solid weight $10 \mathrm{mg}, T=298 \mathrm{~K}$ ). 


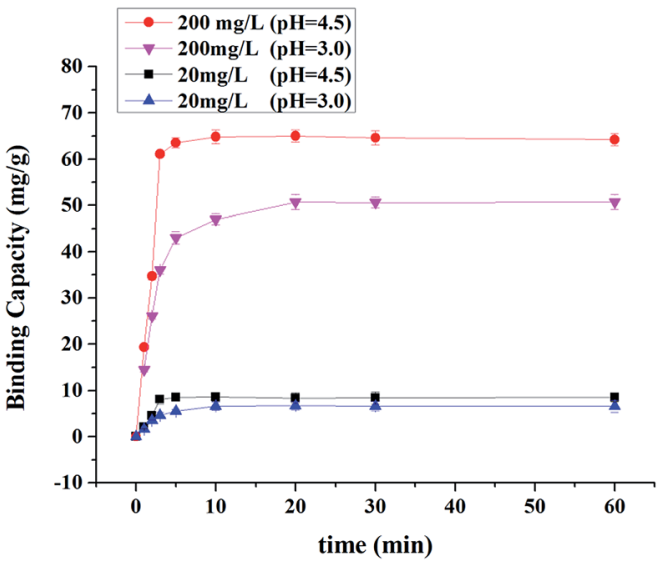

Fig. 11 Adsorption kinetics of CrIMS (used $10 \mathrm{~mL}$ solution, $10 \mathrm{mg}$ adsorbent, $T=298 \mathrm{~K}$ ).

In this work, we intended to construct a novel $\mathrm{Cr}$ (III) ions imprinting mesoporous silica material to remove $\mathrm{Cr}$ (III) ions from effluent at low $\mathrm{pH}$. Moreover, when the $\mathrm{pH}$ value was below 4.5, the binding capacity was low. Besides, the initial $\mathrm{pH}$ of the real sample we chose is 3.0. Therefore, we chose $\mathrm{pH} 4.5$ and $\mathrm{pH} 3.0$ for conducting following adsorption tests.

The results of isothermal adsorption experiments were presented in Fig. 10. The binding capacities of $\mathrm{Cr}$ (III) ions on the CrIMS and NIMS were nonlinear and increased with the increase of the initial concentration of $\mathrm{Cr}$ (III) ions. The CrIMS reached a saturated adsorption value (approximately $63 \mathrm{mg} \mathrm{g}^{-1}$ ) when the initial concentration of $\mathrm{Cr}$ (III) ions was $200 \mathrm{mg} \mathrm{L}^{-1}$ at $\mathrm{pH} 4.5$. At $\mathrm{pH} 3.0$, the binding capacity still reached $51 \mathrm{mg} \mathrm{g}^{-1}$. The two saturated adsorption values were both higher than that of NIMS. These results proved that the effect of imprinting combined with the chelate action enhanced the affinities with $\mathrm{Cr}$ (III) ions and binding capacities of CrIMS which owns specifically binding sites.

\subsection{Kinetic study}

The kinetic study was undertaken at two different concentrations (20 and $200 \mathrm{mg} \mathrm{L}^{-1}$ ) of $\mathrm{Cr}$ (III) ions. As the results were

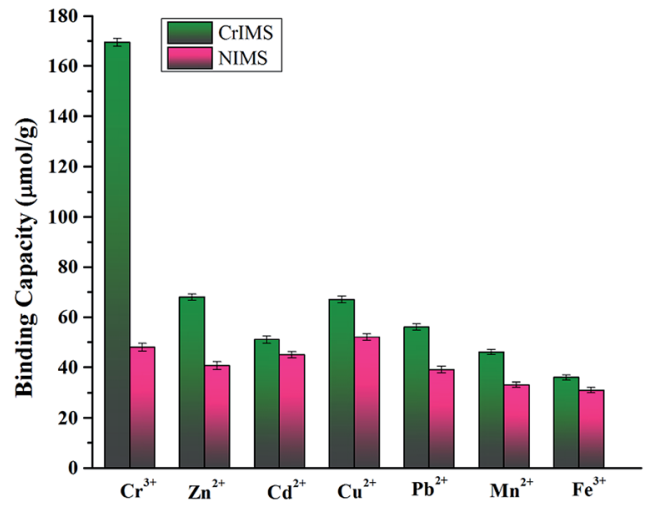

Fig. 12 Selective adsorption experiments of CrIMS and NIMS (experimental conditions: initial concentrations of metal ions $1 \mathrm{mmol} \mathrm{L}^{-1}$, $10 \mathrm{~mL}$ solution at $\mathrm{pH} 4.5,10 \mathrm{mg}$ adsorbent, $T=298 \mathrm{~K}$ ).



Fig. 13 Reusability of CrIMS (experimental conditions: $10 \mathrm{~mL}$ of $200 \mathrm{mg} \mathrm{L}^{-1} \mathrm{Cr}(\mathrm{II})$ ion solution at $\mathrm{pH} 4.5,10 \mathrm{mg}$ adsorbent, $T=298 \mathrm{~K}$ ).

shown in Fig. 11, at the same $\mathrm{pH}$, equilibrium adsorption time is longer when the initial concentration of $\mathrm{Cr}$ (III) ions is higher. For the $\mathrm{Cr}(\mathrm{III})$ ions concentration of $20,200 \mathrm{mg} \mathrm{L}^{-1}$, the time to reach equilibrium was $3 \mathrm{~min}$ and $5 \mathrm{~min}$ at $\mathrm{pH} 4.5$ respectively, which was much shorter than that of typical MIPs, ${ }^{43}$ and it corresponded with common imprinted mesoporous silica. ${ }^{37,44}$ The short equilibrium adsorption time resulted from the nanometer-sized wall thicknesses and narrow pore size distribution of the mesoporous silica, which significantly enhanced the specific surface area and accelerated mass diffusion and transportation of adsorption processes. ${ }^{35}$ Therefore, the $\mathrm{Cr}$ (III) ions were more accessible to the binding sites of imprinted mesoporous silica. We also found the $\mathrm{pH}$ could affect the equilibrium adsorption time. For the $\mathrm{Cr}(\mathrm{III})$ ions concentration of 20 and $200 \mathrm{mg} \mathrm{L}^{-1}$, the time to reach equilibrium was $10 \mathrm{~min}$ and $20 \mathrm{~min}$ at $\mathrm{pH} 3.0$, respectively.

\subsection{Selectivity study}

In order to investigate the ability of selectively recognition of CrIMS, we chose $\mathrm{Zn}^{2+}, \mathrm{Cd}^{2+}, \mathrm{Cu}^{2+}, \mathrm{Pb}^{2+}, \mathrm{Mn}^{2+}$ and $\mathrm{Fe}^{3+}$ to

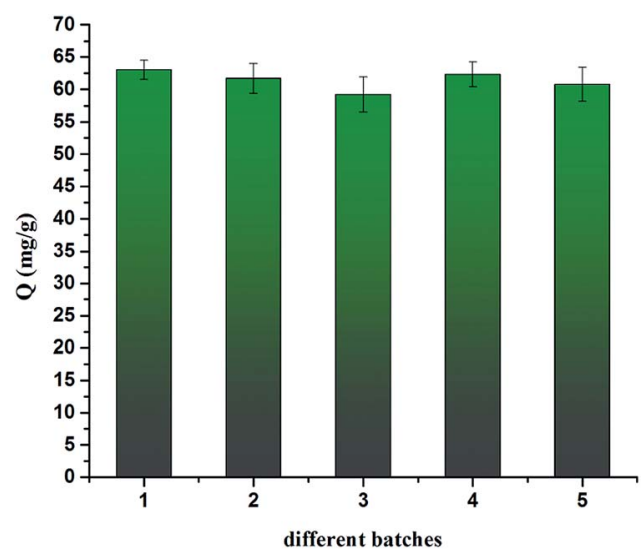

Fig. 14 Reproducibility of CrIMS (experimental conditions: $10 \mathrm{~mL}$ of $200 \mathrm{mg} \mathrm{L}^{-1} \mathrm{Cr}(\mathrm{III})$ ion solution at $\mathrm{pH} 4.5,10 \mathrm{mg}$ adsorbent, $T=298 \mathrm{~K}$ ). 
Table 1 Comparison of the reported adsorbents for $\mathrm{Cr}$ (III) ions

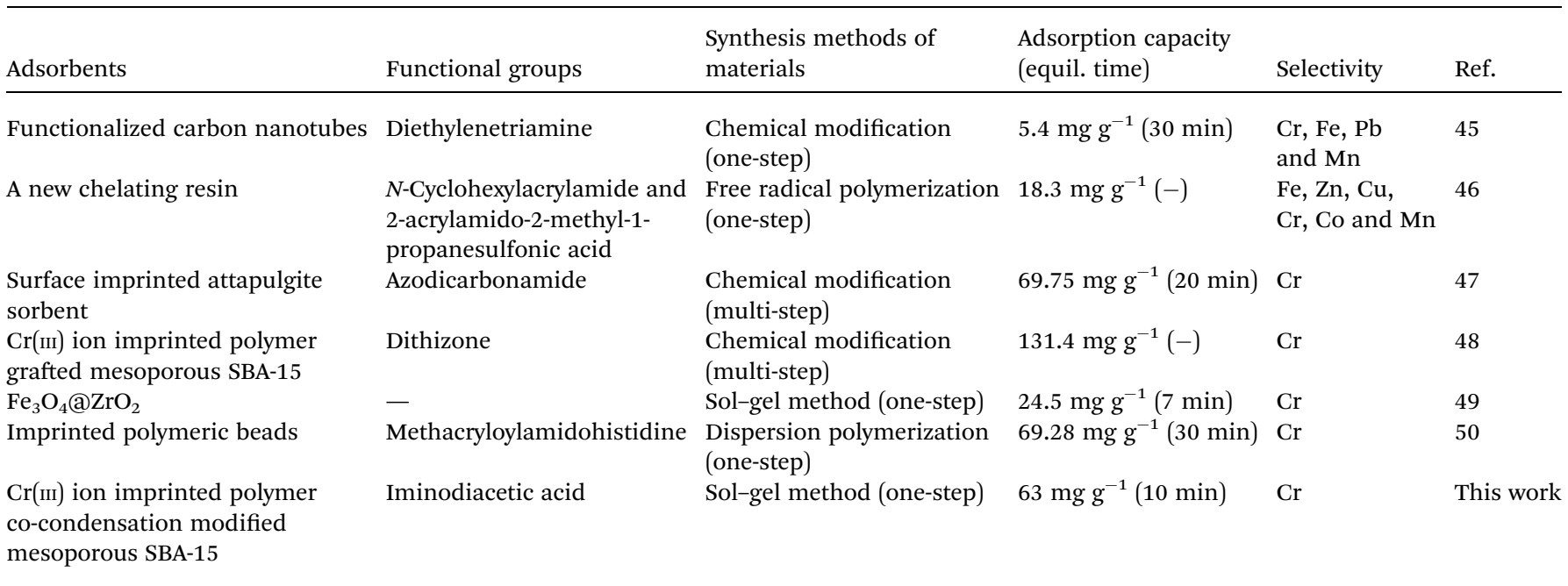

performed competitive adsorption tests. These ions could coexist in effluents with $\mathrm{Cr}$ (III) ions, and they have similar ionic radius with $\mathrm{Cr}(\mathrm{III})$ ions. In addition, $\mathrm{Fe}^{3+}$ has the same charge with $\mathrm{Cr}^{3+}$ and is often detected at high concentrations in some water samples. As shown in Fig. 12, the adsorption capacities of NIMS toward all the ions were not significantly different, while that of CrIMS to $\mathrm{Cr}($ III) ion was much higher than its adsorption capacities toward $\mathrm{Zn}^{2+}, \mathrm{Cd}^{2+}, \mathrm{Cu}^{2+}, \mathrm{Pb}^{2+}, \mathrm{Mn}^{2+}$ or $\mathrm{Fe}^{3+}$. The results indicated that the CrIMS possessed specifically binding sites and highly selective recognition ability. However, since the IDA groups were distributed randomly in the mesoporous silica, NIMS hardly possessed selective recognition ability.

\subsection{Reusability and reproducibility}

Reusability and reproducibility are two nonnegligible factors in real sample treatment of adsorbents. To test the reusability, the CrIMS was used 8 times to absorb $\mathrm{Cr}$ (III) ions at $\mathrm{pH} 4.5$. The results of experiments were presented in Fig. 13. The adsorption capacity decreased slightly after being used. The adsorption efficiency of the sample still reached $94.1 \%$ after eight cycles, proving that CrIMS possessed good reusable property. We synthesized 5 batches of CrIMS to examine the reproducibility of the adsorbents with the same synthesis method. The samples of 5 batches of CrIMS adsorbed $\mathrm{Cr}(\mathrm{III})$ ions at the concentration of $200 \mathrm{mg} \mathrm{L}^{-1}$ at pH 4.5. The results were displayed in Fig. 14. The related standard deviation for reproducibility ranged from $2.38 \%$ to $4.56 \%$. The results indicated that the synthesis method can guarantee a good reproducibility of CrIMS.

\subsection{Application of actual effluent sample}

The samples of electroplating effluent were collected in polyethylene bottles from Dawang Electroplating Industrial Park (Guangdong, China) with $\mathrm{pH} 3.0$ and $\mathrm{Cr}(\mathrm{III})$ ions concentration of $26 \mathrm{mg} \mathrm{L}^{-1}$. After the raw sample was filtered, $3.5 \mathrm{~g}$ of CrIMS was added into $1 \mathrm{~L}$ of the sample, and the residual concentration of $\mathrm{Cr}$ (III) ions in the solution was $0.05 \mathrm{mg} \mathrm{L}^{-1}$. In order to improve the adsorption capacity, the $\mathrm{pH}$ of water sample was adjusted to 4.5 . Then, $2.6 \mathrm{~g}$ of CrIMS was used to adsorb $\mathrm{Cr}(\mathrm{III})$ ions from $1 \mathrm{~L}$ of the sample. The residual concentration of $\mathrm{Cr}(\mathrm{III})$ ions was $0.02 \mathrm{mg} \mathrm{L}^{-1}$. The concentrations of $\mathrm{Cr}$ (III) ions of the effluents after treatment were both less than the discharge standard of China $\left(0.1 \mathrm{mg} \mathrm{L}^{-1}\right)$.

\subsection{Comparison with other reported adsorbents}

The comparison among CrIMS and other reported adsorbents was displayed in Table 1 . The simply chemistry modified materials hardly showed selectivity to $\mathrm{Cr}$ (III) ions. Ion imprinting technology can enhance the adsorption selectivity of adsorbents. Combined with mesoporous materials , CrIMS possessed the advantages of faster equilibrium, higher absorption capacity.

\section{Conclusions}

In this work, we combined ion imprinting polymers with highly ordered mesoporous silica for removal of $\mathrm{Cr}(\mathrm{III})$ ions from acidic effluents. The obtained CrIMS possessed large surface area and highly ordered pore arrays, which was the typical structure of SBA-15 mesoporous materials. Moreover, CrIMS also showed favourable selective recognition performance. The specific binding sites were distributed in ion imprinting mesoporous silica, which remarkably enhanced the accessibility for the targets and imprinted cavities. CrIMS presented higher selectivity adsorption capacity towards $\mathrm{Cr}$ (III) ions in an acidic solution. This effective synthesis method is convenient and can guarantee good reusability and reproducibility. In the actual treatment of effluent, the concentration of $\mathrm{Cr}$ (III) ions of the electroplating effluent after treatment is below the discharge standard of $\mathrm{Cr}(\mathrm{III})$ ions of China.

\section{Conflict of interest}

There are no conflicts of interest to declare. 


\section{Acknowledgements}

We gratefully acknowledge the financial support from the NSFC-GD Joint Foundation of the Key Projects (No. U1201234) and National Natural Science Foundation of China (No. 21275057).

\section{References}

1 Z. Zeng, L. Wang, A. Liang and J. Zhang, Electrochim. Acta, 2006, 52, 1366-1373.

2 J. Kotaś and Z. Stasicka, Environ. Pollut., 2000, 107, 263-283. 3 Q. Duan, J. Lee, Y. Liu, H. Chen and H. Hu, Bull. Environ. Contam. Toxicol., 2016, 97, 303-309.

4 G. d. C. Cunha, J. A. Peixoto, D. R. de Souza, L. P. C. Romão and Z. S. Macedo, Green Chem., 2016, 18, 5342-5356.

5 B. Zawisza, R. Skorek, G. Stankiewicz and R. Sitko, Talanta, 2012, 99, 918-923.

6 M. M. López Guerrero, E. Vereda Alonso, J. M. Cano Pavón, M. T. Siles Cordero and A. García de Torres, J. Anal. At. Spectrom., 2012, 27, 682-688.

7 G. Zhang, D. Chen, W. Zhao, H. Zhao, L. Wang, W. Wang and T. Qi, Chem. Eng. J., 2016, 302, 233-238.

8 M. J. Manos and M. G. Kanatzidis, Chem. Sci., 2016, 7, 48044824.

9 M. Zhang, L. Song, H. Jiang, S. Li, Y. Shao, J. Yang and J. Li, J. Mater. Chem. A, 2017, 5, 3434-3446.

10 N. Meunier, P. Drogui, C. Montané, R. Hausler, G. Mercier and J.-F. Blais, J. Hazard. Mater., 2006, 137, 581-590.

11 G. Cimino, A. Passerini and G. Toscano, Water Res., 2000, 45, 2207-2212.

12 J. R. Rangel-Mendez, R. Monroy-Zepeda, E. Leyva-Ramos, P. E. Diaz-Flores and K. Shirai, J. Hazard. Mater., 2009, 162, 503-511.

13 L. Mercier and C. Detellier, Environ. Sci. Technol., 1995, 29, 1318-1323.

14 V. Ravindran, M. R. Stevens, B. N. Badriya and M. Pirbazari, AIChE J., 1999, 45, 1135-1146.

15 G. Wu, Z. Wang, J. Wang and C. He, Anal. Chim. Acta, 2007, 582, 304-310.

16 X. Jing, F. Liu, X. Yang, P. Ling, L. Li, C. Long and A. Li, J. Hazard. Mater., 2009, 167, 589-596.

17 V. K. Gupta, S. Agarwal and T. A. Saleh, Water Res., 2011, 45, 2955-2962.

18 R. He, W. Li, D. Deng, W. Chen, H. Li, C. Wei and Y. Tang, J. Mater. Chem. A, 2015, 3, 9789-9798.

19 J. S. Beck, J. C. Vartuli, W. J. Roth, M. E. Leonowicz, C. T. Kresge, K. D. Schmitt, C. T.-W. Chu, D. H. Olson, E. W. Sheppard, S. B. McCullen, J. B. Higgins and J. L. Schlenker, J. Am. Chem. Soc., 1992, 114, 10834-10843.

20 S. Wongsakulphasatch, W. Kiatkittipong, J. Saiswat, B. Oonkhanond, A. Striolo and S. Assabumrungrat, Inorg. Chem. Commun., 2014, 46, 301-304.

21 M. Oschatz, W. S. Lamme, J. Xie, A. I. Dugulan and K. P. de Jong, ChemCatChem, 2016, 8, 2846-2852.

22 A. Bigham, S. A. Hassanzadeh-Tabrizi, M. Rafienia and H. Salehi, Ceram. Int., 2016, 42, 17185-17191.
23 Y. Du, S. Guo, S. Dong and E. Wang, Biomaterials, 2011, 32, 8584-8592.

24 A. Benhamou, M. Baudu, Z. Derriche and J. P. Basly, J. Hazard. Mater., 2009, 171, 1001-1008.

25 S. Lacasta, V. Sebastáin, C. Casado, Á. Mayoral, P. Romero, Á. Larrea, E. Vispe, P. López-Ram-de-Viu, S. Uriel and J. Coronas, Chem. Mater., 2011, 23, 1280-1287.

26 C. Tsai, Y. Pan, C. Ting, S. Vetrivel, A. S. T. Chiang, G. T. K. Fey and H. Kao, Chem. Commun., 2009, 33, 5018-5020.

27 G. Vlatakis, L. I. Andersson, R. Müller and K. Mosbach, Nature, 1993, 361, 645-647.

28 D. Dechtrirat, N. G. Eichelmann, F. F. Bier and F. W. Scheller, Adv. Funct. Mater., 2014, 24, 2233-2239.

29 L. Chen, S. Xu and J. Li, Chem. Soc. Rev., 2011, 40, 2922-2942.

30 L. Uzun and A. P. F. Turner, Biosens. Bioelectron., 2016, 76, 131-144.

31 L. Tan, Z. Yu, X. Zhou, D. Xing, X. Luo, R. Peng and Y. Tang, J. Chromatogr. A, 2015, 1141, 69-76.

32 H. Niu, Y. Yang and H. Zhang, Biosens. Bioelectron., 2015, 74, 440-446.

33 L. Chen, X. Wang, W. Lu, X. Wu and J. Li, Chem. Soc. Rev., 2016, 45, 2137-2211.

34 Y. Hoshino, R. C. Ohashi and Y. Miura, Adv. Mater., 2014, 26, 3718-3723.

35 Y. Chen, D. Li, Z. Bie, X. He and Z. Liu, Anal. Chem., 2016, 88, 1447-1454.

36 Y. Chen, X. Li, D. Yin, D. Li, Z. Bie and Z. Liu, Chem. Commun., 2015, 51, 10929-10932.

37 X. Zheng, E. Liu, F. Zhang, Y. Yan and J. Pan, Green Chem., 2016, 18, 5031-5040.

38 F. Hoffmann, M. Cornelius, J. Morell and M. Fröba, Angew. Chem., Int. Ed., 2006, 45, 3216-3251.

39 Y. Wang, L. Song, L. Zhu, B. Guo, S. Chen and W. Wu, Dalton Trans., 2014, 43, 3739-3749.

40 T. Kobayashi, O. Lafon, A. S. L. Thankamony, I. I. Slowing, K. Kandel, D. Carnevale, V. Vitzthum, H. Vezin, J.-P. Amoureux, G. Bodenhausen and M. Pruski, Phys. Chem. Chem. Phys., 2013, 15, 5553-5562.

41 S. Inagaki, I. Kawamura, Y. Sasaki, K. Yoshida, Y. Kubota and A. Naito, Phys. Chem. Chem. Phys., 2013, 15, 13523-13531.

$42 \mathrm{H}$. Liu and W. Chen, RSC Adv., 2015, 5, 27034-27042.

43 T. Chang, Y. Liu, X. Yan, S. Liu and H. Zheng, RSC Adv., 2016, 6, 66297-66306.

44 S. Cen, W. Li, S. Xu, Z. Wang, Y. Tang, H. Wang and C. Wei, RSC Adv., 2017, 7, 7996-8003.

45 X. Zhu, Y. Cui, X. Chang and H. Wang, Talanta, 2016, 146, 358-363.

46 T. Daşbaşı, Ş. Saçmacı, N. Çankaya and C. Soykan, Food Chem., 2016, 211, 68-73.

47 Z. Li, W. Kou, S. Wu and L. Wu, Anal. Methods, 2017, 9, 32213229.

48 M. Jamshidi, M. Ghaedi, K. Dashtian and S. Hajati, RSC Adv., 2015, 5, 105789-105799.

49 Y. Wu, J. Zhang, J. Liu, L. Chen, Z. Deng, M. Han, X. Wei, A. Yu and H. Zhang, Appl. Surf. Sci., 2012, 258, 6772-6776.

50 E. Birlik, A. Ersöz, E. Açıkkalp, A. Denizli and R. Say, J. Hazard. Mater., 2007, 140, 110-116. 